\title{
Stomach-Selective Gene Transfer Following the Administration of Naked Plasmid DNA onto the Gastric Serosal Surface in Mice
}

\author{
Junzo Nakamura, ${ }^{* a}$ Shintaro Fumoto, ${ }^{a}$ Keiko ShoJI,${ }^{a}$ Yukinobu Kodama, ${ }^{a}$ Junya Nishi, ${ }^{a}$ \\ Mikiro NAKASHIMA, ${ }^{a}$ Hitoshi SASAKI, ${ }^{b}$ and Koyo NishidA ${ }^{a}$ \\ ${ }^{a}$ Graduate School of Biomedical Sciences, Nagasaki University; 1-14 Bunkyo-machi, Nagasaki 852-8521, Japan: and \\ ${ }^{b}$ Department of Hospital Pharmacy, Nagasaki University Hospital of Medicine and Dentistry; 1-7-1 Sakamoto, Nagasaki \\ 852-8501, Japan. Received March 13, 2006; accepted June 15, 2006
}

\begin{abstract}
The purpose of the present study was to achieve a stomach-selective gene transfer following the administration of naked plasmid DNA (pDNA) onto the gastric serosal surface in mice. Gene expression in the stomach and other tissues was evaluated by firefly luciferase activity. Six hours after gastric serosal surface instillation of naked pDNA, high gene expression in the stomach was observed. On the contrary, intravenous and intraperitoneal injection of naked pDNA exhibited no detectable gene expression. Following instillation of naked pDNA onto the gastric serosal surface, gene expression in the stomach was significantly higher than in other tissues. Gene expression in the stomach was highest $12 \mathrm{~h}$ after the instillation and thereafter decreased gradually. Utilizing a glass-made diffusion cell that is able to limit the contact dimension between the gastric serosal surface and the naked pDNA solution administered, site-specific gene expression in the stomach was achieved. This novel gene transfer method is expected to be a safe and effective treatment against serious stomach diseases.
\end{abstract}

Key words gene therapy; plasmid DNA; stomach; transfection; mouse; luciferase

The stomach is a digestive organ that is essential for nutrient intake. An acidic environment in the stomach is required for the digestive system and a barrier function against acidic $\mathrm{pH}$ is necessary. Alcohol, drugs, stress, and Helicobacter pylori reduce barrier function and cause gastritis and gastric ulcer. Moreover, gastric cancer is one of the most common malignant tumors in the world. For treatment of these diseases, gene therapy is a promising approach and trials for gastric ulcer ${ }^{1)}$ and carcinoma models ${ }^{2-4)}$ have been performed. The gene delivery systems in vivo can be categorized as viral and non-viral approaches. ${ }^{5,6)}$ Safety in usage of viral vectors for clinical gene therapy is not yet sufficient, ${ }^{7,8)}$ whereas naked plasmid DNA (pDNA), which is a typical non-viral vector, has safety advantages compared with a viral vector. Recently, gene transfection efficiency using non-viral vectors has improved due to the development of various gene carriers such as cationic liposome. ${ }^{9}{ }^{910}$ However, transfection utilizing naked pDNA is the simplest and safest non-viral gene delivery system since naked pDNA can be used without consideration of cytotoxicity by the gene carrier. When foreign genes were administered via the vasculature route, they were distributed to the whole body through the bloodstream, leading to inadequate organ-selective or diseased site-selective gene delivery, and were rapidly degraded by reticuloendothelial cells (liver Kupffer cell, etc.) and nuclease in the blood. ${ }^{11)}$ Although it was previously reported that the organselective gene transfection using naked pDNA had been achieved by direct injection, electroporation, gene gun and so on, ${ }^{12-14)}$ there is great concern about safety because these procedures require physical force against the organs; consequently, the continuous administration of pDNA is limited.

We previously developed a method for application of drugs to the surface of intraperitoneal organs such as liver, ${ }^{15-24)}$ kidney, ${ }^{25-29)}$ and stomach, ${ }^{30-32)}$ and found it to be a useful method for site-selective drug delivery to these organs. Furthermore, we reported on site-selective gene expression following the instillation of naked pDNA to the liver surface $^{33-36)}$ and kidney surface ${ }^{37)}$ in mice. The present study was undertaken to examine a stomach-selective gene transfer following the administration of naked pDNA onto the gastric serosal surface in mice.

\section{MATERIALS AND METHODS}

Materials All chemicals were of the highest purity available.

Animals Male ddY mice were housed in a cage in an air-conditioned room and maintained on a standard laboratory diet (MF, Oriental Yeast, Co., Ltd., Tokyo, Japan) and water ad libitum. All animal experiments in the present study conformed to the Guidelines for Animal Experimentation of Nagasaki University.

Construction and Preparation of pDNA pCMV-luciferase was constructed by subcloning the Hind III/Xba I firefly luciferase cDNA fragment from pGL3-control vector (Promega, Madison, WI, U.S.A.) into the polylinker of pcDNA3 vector (Invitrogen, Carlsbad, CA, U.S.A.). pDNA was amplified in the Escherichia coli strain DH5 $\alpha$, isolated, and purified using an EndoFree ${ }^{\circledR}$ Plasmid Giga Kit (QIAGEN $\mathrm{GmbH}$, Hilden, Germany). pDNA dissolved in 5\% glucose solution was stored at $-20^{\circ} \mathrm{C}$ prior to experiments.

In Vivo Gene Expression Experiments Five-week-old ddY male mice $(22.0-38.0 \mathrm{~g})$ were anesthetized with sodium pentobarbital $(40-60 \mathrm{mg} / \mathrm{kg}$, intraperitoneal injection). The left peritoneum was dissected and the stomach was exposed. pDNA was instilled onto the serosal surface of the stomach using a micropipette (PIPETMAN ${ }^{\circledR}$, GILSON, Inc., Villiers-le-Bel, France). Immediately, the peritoneum was sutured. Mice were kept lying on their back for $1 \mathrm{~h}$, and then were freed in the cage. At appropriate time intervals, the mice were sacrificed, and the stomach, liver, kidney (left and right), spleen, lung and heart were removed. The tissues were washed twice with saline and homogenized with a lysis buffer which consisted of $0.1 \mathrm{~m}$ Tris/ $\mathrm{HCl}$ buffer $(\mathrm{pH} 7.8)$ con- 
taining $0.05 \%$ Triton X-100 and 2 mm EDTA. ${ }^{38)}$ The volumes of the lysis buffer added were $4 \mu \mathrm{l} / \mathrm{mg}$ for liver and $5 \mu \mathrm{l} / \mathrm{mg}$ for other tissues. After three cycles of freezing and thawing, the homogenates were centrifuged at $15610 \times \boldsymbol{g}$ for $5 \mathrm{~min}$. The supernatants were stored at $-20^{\circ} \mathrm{C}$ until the luciferase assays were performed. Twenty microliters of supernatant was mixed with $100 \mu$ l of luciferase assay buffer (Picagene ${ }^{\circledR}$, Toyo Ink Mfg. Co., Ltd., Tokyo) and the light produced was immediately measured using a luminometer (MiniLumat LB 9506, BERTHOLD TECHNOLOGIES, Bad Wildbad, Germany). The luciferase activity is indicated as the relative light units (RLU) per gram of tissue.

In Situ Gene Expression Experiments Five-week-old ddY male mice $(22.0-38.0 \mathrm{~g})$ were anesthetized with sodium pentobarbital $(40-60 \mathrm{mg} / \mathrm{kg}$, intraperitoneal injection). The left peritoneum was dissected and a glass-made cylindrical diffusion cell (i.d. $6 \mathrm{~mm}$, effective area $0.28 \mathrm{~cm}^{2}$ ) was attached to the gastric serosal surface (Fig. 1) with a thin film of surgical adhesive (Aron Alpha, Sankyo Co., Ltd., Tokyo). Naked pDNA was added directly into the diffusion cell, and the top of the diffusion cell was sealed with a piece of aluminum foil to prevent evaporation of the pDNA solution. After $10 \mathrm{~min}$, the pDNA solution was removed from the diffusion cell and the gastric serosal surface in the diffusion cell was washed with $5 \%$ glucose solution $(100 \mu \mathrm{l}) 10$ times. After the diffusion cell was removed from the stomach, the peritoneum was sutured. Macroscopical change of the gastric serosal surface was not recognized. At $6 \mathrm{~h}$, the mice were sacrificed, and the stomach, liver, kidney (left and right), spleen, lung and heart were removed. To evaluate the intragastric distribution of gene expression, the stomach was divided into two sections. Site 1 and site 2 are site of diffusion cell attachment (i.d. $9 \mathrm{~mm}$, area $0.64 \mathrm{~cm}^{2}$ ) and other site excluding site 1 (Fig. 1). The following process was the same as in vivo gene expression experiments.

Statistical Analysis Statistical comparisons were performed by one-way ANOVA and subsequent Tukey's multiple comparison tests.

\section{RESULTS AND DISCUSSION}

Investigation of gene therapy for stomach diseases is actively proceeding for gastric cancer. Surgical excision of both primary and metastatic tumors is the recommended therapy for gastric cancer. However, there are many cases of multiple metastases to lymph nodes, disseminated metastasis of peritoneum, and post-operative systemic metastasis for which no surgical treatment is available. Cancer gene therapy is one of the promising techniques for a metastatic tumor along with the primary tumor. ${ }^{39)}$ In most cases, viral vector has been used as the gene delivery method to the stomach, but selectivity and safety concerns have been raised about the viral vector. There have been attempts to improve these problems by use of an adenoviral vector with a cancer specific promoter $^{40)}$ and an adenoviral vector targeted to the specific molecule expressed on gastric cancer cells in vitro. ${ }^{41)}$ However, immunogenicity of adenovirus restricts safety and efficacy in repeated administration. Thus, we developed a novel, safe and stomach-selective gene delivery method instilling naked pDNA onto the gastric serosal surface.

We administered naked pDNA intravenously, intraperi-

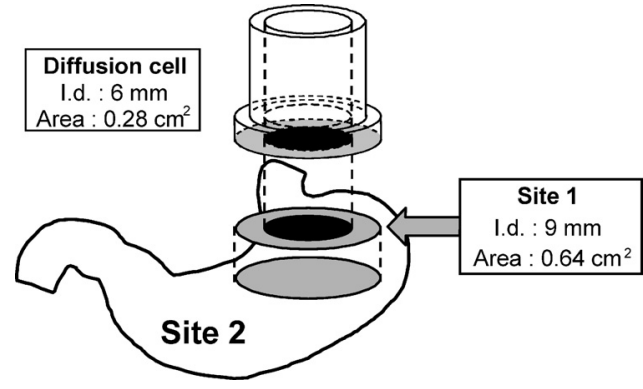

Fig. 1. Scheme of the Stomach Divided into Site 1 and 2 in Mice

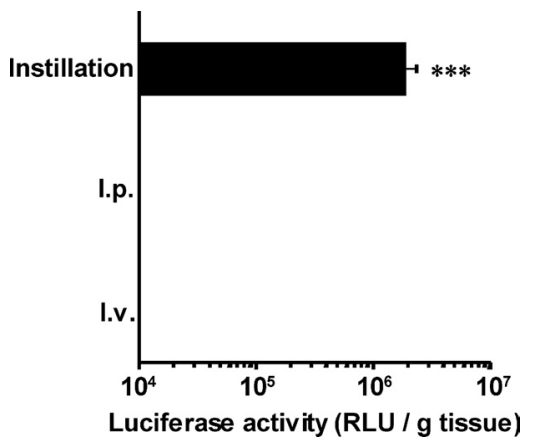

Fig. 2. Gene Expression in Stomach $6 \mathrm{~h}$ after Gastric Serosal Surface Instillation, Intraperitoneal (i.p.) Administration and Intravenous (i.v.) Administration of pDNA at a Dose of $30 \mu \mathrm{g}(30 \mu \mathrm{l})$ in Mice

Each value represents the mean \pm S.E. of at least six experiments. Significantly different from i.p. and i.v. administration $(* * * p<0.001)$.

toneally and instilled it onto the gastric serosal surface. Six hours later, luciferase activity in the stomach was determined (Fig. 2). The gene expression levels represent more than $3 \times 10^{3} \mathrm{RLU} / \mathrm{g}$ tissues because each tissue mixed with substrates without the instillation of naked pDNA showed approximately $3 \times 10^{3} \mathrm{RLU} / \mathrm{g}$ tissues. Therefore, the results represent greater than $10^{4} \mathrm{RLU} / \mathrm{g}$ tissues in Fig. 2, which was considered as stable gene expression. Gastric serosal surface instillation of naked pDNA resulted in high gene expression in the stomach, while intravenous or intraperitoneal injection exhibited no detectable gene expression. In our previous reports, ${ }^{33,34)}$ the gene expression was little detected in liver, kidney and spleen following the intraperitoneal administration of pDNA.

Next, we measured tissue distribution of gene expression $6 \mathrm{~h}$ after gastric serosal surface instillation of naked pDNA. Figure 3 indicates gene expression in the stomach, liver, kidney (left and right), spleen, lung, and heart after instillation onto the gastric serosal surface. Gene expression in the stomach was significantly higher than those in other tissues, and the expression level in the stomach was two times higher than that in the spleen and 300 times higher than that in the heart, which had the lowest value. These results may be due to the position of spleen, liver and left kidney that is close to the stomach, which would easily cause diffusion of the naked pDNA solution to the spleen, liver and left kidney. Thus, instillation of naked pDNA onto the gastric serosal surface is a useful method for stomach-selective gene transfer.

Figure 4 exhibits the time course of gene expression after gastric serosal surface instillation of naked pDNA. Gene expression in the stomach was detected $2 \mathrm{~h}$ after instillation, and $12 \mathrm{~h}$ after instillation reached a peak level. After that, 


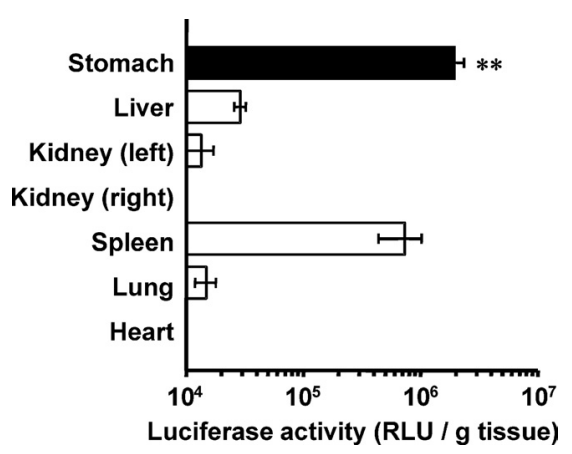

Fig. 3. Gene Expression in Stomach, Liver, Kidney (Left and Right), Spleen, Lung and Heart $6 \mathrm{~h}$ after Gastric Serosal Surface Instillation of pDNA at a Dose of $30 \mu \mathrm{g}(30 \mu \mathrm{l})$ in Mice

Each value represents the mean \pm S.E. of eight experiments. Significantly different from other tissues $(* * p<0.01)$

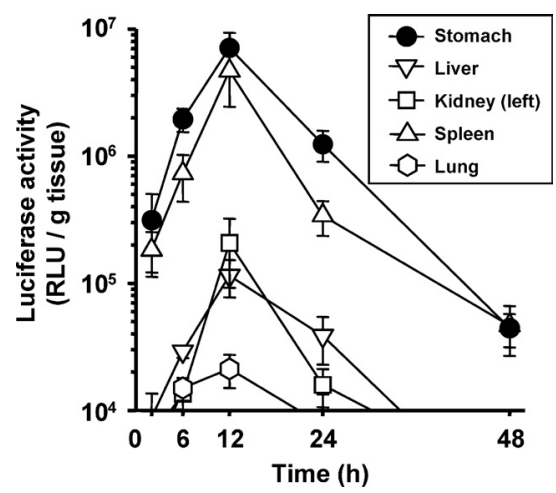

Fig. 4. Time Course of Gene Expression in Stomach, Liver, Kidney (Left), Spleen and Lung up to $48 \mathrm{~h}$ after Gastric Serosal Surface Instillation of pDNA at a Dose of $30 \mu \mathrm{g}(30 \mu \mathrm{l})$ in Mice

Each value represents the mean \pm S.E. of at least six experiments.

gene expression in the stomach decreased gradually but it was still detectable at $48 \mathrm{~h}$. Gene expression in the stomach was transient, probably due to instability of naked pDNA in both intracellular and extracellular space. Thus, it is necessary to perform repeated administration or to develop improved dosage form such as a controlled release formulation for clinical use of gastric serosal administration of naked pDNA. In this regard, the gastric serosal surface instillation of naked pDNA is not stressful to the stomach, so that continuous administration might be possible using a catheter to enable long-term gastric gene transfection.

Effect of instillation dose on gene expression $6 \mathrm{~h}$ after gastric serosal surface instillation of naked pDNA was investigated (Fig. 5). One microgram of naked pDNA exhibited detectable gene expression in the stomach, and the gene expression increased gradually up to $30 \mu \mathrm{g}$. Figure 6 indicates the effect of instillation volume on the gene expression $6 \mathrm{~h}$ after gastric serosal surface instillation of naked pDNA. Increasing the instillation volume tended to slightly decrease the gene expression in the stomach, but the differences were not significant.

We selected an experimental system utilizing a glass-made cylindrical diffusion cell attached to the gastric serosal surface (Fig. 1). This system enabled us to examine gene uptake from the gastric serosal surface without interference by uptake from other tissues. Figure 7 shows the gene expression 6 $h$ after gastric serosal surface administration of naked pDNA

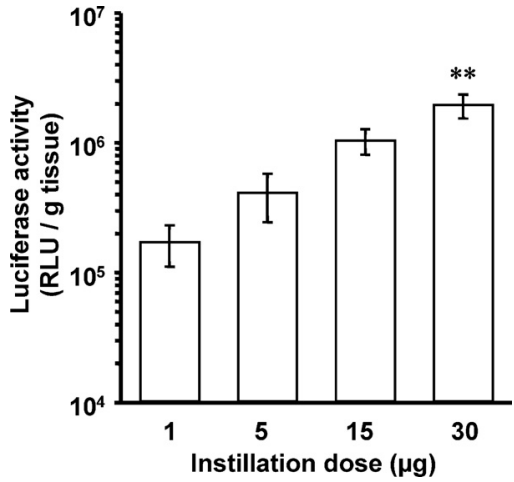

Fig. 5. Effect of Instillation Doses on Gene Expression in Stomach $6 \mathrm{~h}$ after Gastric Serosal Surface Instillation of pDNA at a Volume of $30 \mu \mathrm{l}$ in Mice

Each value represents the mean \pm S.E. of at least seven experiments. Significantly different from the result at $1 \mu \mathrm{g}$ and $5 \mu \mathrm{g}(* * p<0.01)$

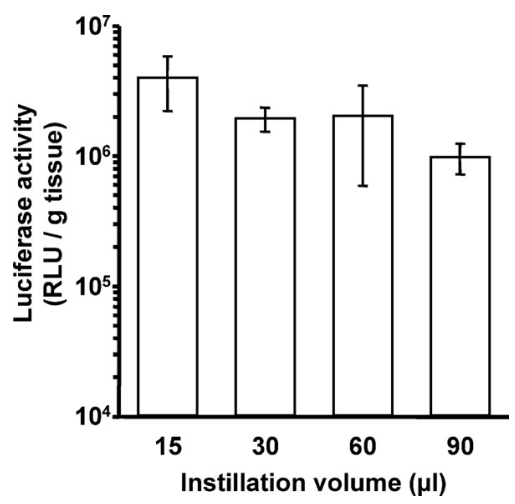

Fig. 6. Effect of Instillation Volumes on Gene Expression in Stomach $6 \mathrm{~h}$ after Gastric Serosal Surface Instillation of pDNA at a Dose of $30 \mu \mathrm{g}$ in Mice

Each value represents the mean \pm S.E. of at least six experiments.

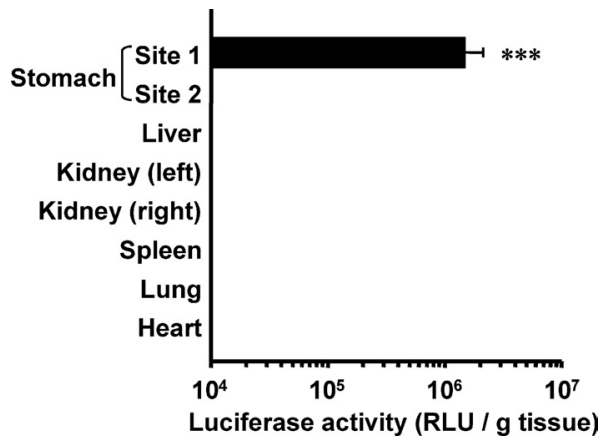

Fig. 7. Gene Expression in Stomach (Site 1 and Site 2), Liver, Kidney (Left and Right), Spleen, Lung and Heart $6 \mathrm{~h}$ after Gastric Serosal Surface Application of pDNA (30 $\mu \mathrm{g}, 30 \mu \mathrm{l})$ Using Diffusion Cell in Mice

Each value represents the mean \pm S.E. of fifteen experiments. Significantly different from site 2 and other tissues $(* * * p<0.001)$.

into the diffusion cell for $10 \mathrm{~min}$. The gene expression was found only in the applied site of the stomach (site 1), and the gene expression level in site 1 was significantly higher than those in other site of the stomach (site 2) and other tissues. These results suggest that naked pDNA was transferred from the gastric serosal surface and transgene product was expressed in the applied site of the stomach.

The stomach-selective gene transfection method is expected to be a safe and effective treatment against gastric 
cancer, which is localized in the stomach. Gastric cancer is generated in the gastric mucosal side and then invades the gastric serosal side. ${ }^{42)}$ Gastric serosal instillation of pDNA encoding an anticancer gene is thought to act primarily against the invasion of gastric cancer to the serosal side, on the contrary, it might be difficult for pDNA to penetrate into the mucosal side. But prophylactic application of gastric serosal instillation of $\mathrm{pDNA}$ combined with the resection of mucosal cancer might be useful to prevent invasion of the remaining cancer cells. Furthermore, we previously reported that gastric serosal surface application of the anticancer drug 5-fluorouracil (5-FU) resulted in comparable distribution of 5 -FU between the mucosal and serosal sides; consequently, 5-FU was efficiently distributed to the mucosal side from the serosal side prior to the distribution to the systemic circulation. $^{32)}$ It was reported that the combination therapy of intratumoral administration of pDNA encoding a proapoptotic gene complexed with a cationic lipopolyamine and anticancer drugs significantly enhanced the antitumor effect against the gastric cancer model. ${ }^{43)}$ Thus, gastric serosal surface application of both an anticancer drug and gene would be a safe and effective strategy. Additionally, suicide gene therapy, which is a combination of the herpes simplex virus thymidine-kinase gene and anticancer prodrug, ${ }^{44)}$ is also a safe strategy and applicable for the gastric serosal surface application method.

Investigations have been reported for treatment of gastric cancer by local, direct injection of adenoviruses encoding Fas ligand ${ }^{2)}$ p53, ${ }^{3)}$ and hepatocyte growth factor antagonist $\mathrm{NK}^{4)}$ genes to subcutaneous tumor of gastric cancer cells, and these indicated suppression of tumor growth. On the other hand, a single local injection of pDNA encoding vascular endothelial growth factor and angiopoietin-1 was shown to stimulate gastric ulcer healing in the rat. ${ }^{1)}$ These genes may be candidates of the gastric serosal surface instillation method for treatment of these gastric diseases.

In summary, we have demonstrated stomach-selective gene transfer following the administration of naked pDNA onto the gastric serosal surface in mice. The transgene expression levels in the stomach were significantly higher than those in other tissues. This novel gene transfer method is expected to be a safe and effective treatment against serious stomach diseases.

Acknowledgments The authors thank Yoko Matsumoto for technical assistance. This work was supported in part by a Grant-in-Aid for Scientific Research from the Ministry of Education, Culture, Sports, Science and Technology, Japan, by a Grant-in-Aid from the Uehara Memorial Foundation, by a Grant-in-Aid from the Mochida Memorial Foundation for Medical and Pharmaceutical Research and by a Grant-in-Aid for Scientific Research from the President of Nagasaki University.

\section{REFERENCES}

1) Jones M. K., Kawanaka H., Baatar D., Szabó I. L., Tsugawa K., Pai R., Koh G. Y., Kim I., Sarfeh I. J., Tarnawski A. S., Gastroenterology, 121, 1040-1047 (2001).

2) Zheng S. Y., Li D. C., Zhang Z. D., Zhao J., Ge J. F., World J. Gastroenterol., 11, 3446-3450 (2005).

3) Ohashi M., Kanai F., Ueno H., Tanaka T., Tateishi K., Kawakami T.,
Koike Y., Ikenoue T., Shiratori Y., Hamada H., Omata M., Gut, 44 366-371 (1999)

4) Heideman D. A. M., van Beusechem V. W., Bloemena E., Snijders P. J. F., Craanen M. E., Offerhaus G. J. A., Derksen P. W. B., de Bruin M., Witlox M. A., Molenaar B., Meijer C. J. L. M., Gerritsen W. R., J. Gene Med., 6, 317-327 (2004).

5) Thomas C. E., Ehrhardt A., Kay M. A., Nat. Rev. Genet., 4, 346-358 (2003).

6) Nishikawa M., Hashida M., Biol. Pharm. Bull., 25, 275-283 (2002).

7) Marshall E., Science, 286, 2244-2245 (1999).

8) Check E., Nature (London), 420, 116-118 (2002).

9) Niidome T., Huang L., Gene Ther, 9, 1647-1652 (2002).

10) Kawakami S., Yamashita F., Nishida K., Nakamura J., Hashida M., Crit. Rev. Ther. Drug Carrier Syst., 19, 171-190 (2002).

11) Kawabata K., Takakura Y., Hashida M., Pharm. Res., 12, 825-830 (1995).

12) Hickman M. A., Malone R. W., Lehmann-Bruinsma K., Sih T. R., Knoell D., Szoka F. C., Walzem R., Carlson D. M., Powell J. S., Hum. Gene Ther., 5, 1477-1483 (1994).

13) Somiari S., Glasspool-Malone J., Drabick J. J., Gilbert R. A., Heller R., Jaroszeski M. J., Malone R. W., Mol. Ther., 2, 178-187 (2000).

14) Lin M. T. S., Pulkkinen L., Uitto J., Yoon K., Int. J. Dermatol., 39, $161-170(2000)$

15) Nishida K., Sato N., Sasaki H., Nakamura J., J. Pharm. Pharmacol., 46, 867-870 (1994).

16) Nishida K., Sato N., Sasaki H., Nakamura J., J. Pharm. Pharmacol., 47, 227-231 (1995)

17) Nishida K., Sato N., Sasaki H., Nakamura J., Biol. Pharm. Bull., 18, 1548-1550 (1995).

18) Nishida K., Sato N., Nakakoga Y., Mukai T., Sasaki H., Nakamura J., J. Pharm. Pharmacol., 49, 976-980 (1997).

19) Nakamura J., Yoshida Y., Mera K., Mukai T., Nishida K., Sasaki H., Biol. Pharm. Bull., 22, 713-715 (1999).

20) Nishida K., Nakakoga Y., Sato N., Kawakami S., Mukai T., Sasaki H., Sakaeda T., Nakamura J., Eur. J. Pharm. Biopharm., 50, 397-402 (2000).

21) Nishida K., Yoshida Y., Mukai T., Kawakami S., Sakaeda T., Nakashima M., Sasaki H., Nakamura J., J. Pharm. Pharmacol., 53, 1341-1346 (2001).

22) Nishida K., Honda T., Nakashima M., Sasaki H., Nakamura J., Biol. Pharm. Bull., 26, 988-993 (2003).

23) Mukai T., Mera K., Nishida K., Nakashima M., Sasaki H., Sakaeda T., Nakamura J., Biol. Pharm. Bull., 25, 1494-1497 (2002).

24) Nishida K., Fujiwara R., Kodama Y., Fumoto S., Mukai T., Nakashima M., Sasaki H., Nakamura J., Pharm. Res., 22, 1331-1337 (2005).

25) Kawakami S., Horimoto T., Nishida K., Hirayama R., Mukai T., Nakashima M., Sasaki H., Sakaeda T., Nakamura J., Biol. Pharm. Bull., 25, 928-930 (2002).

26) Nakamura J., Horimoto T., Hirayama R., Mukai T., Nakashima M., Sasaki H., Nishida K., Biol. Pharm. Bull., 26, 1049-1051 (2003).

27) Nakamura J., Horimoto T., Hirayama R., Mukai T., Nakashima M., Sasaki H., Nishida K., Biol. Pharm. Bull., 26, 1761-1764 (2003).

28) Nishida K., Tomiyama N., Mukai T., Nakashima M., Sasaki H., Nakamura J., Eur. J. Pharm. Biopharm., 58, 705-711 (2004).

29) Nishida K., Kamenosono M., Kuma A., Fumoto S., Mukai T., Nakashima M., Sasaki H., Nakamura J., J. Drug Target., 13, 215-223 (2005).

30) Nakamura J., Tsurumaru A., Mera K., Mukai T., Nishida K., Sasaki H., Pharm. Pharmacol. Commun., 5, 519-522 (1999).

31) Mukai T., Tsurumaru A., Mera K., Nishida K., Nakamura J., Sasaki H., Sakaeda T., Pharm. Pharmacol. Commun., 5, 609-614 (1999).

32) Nakamura J., Kobayashi K., Fumoto S., Nishi J., Mukai T., Nakashima M., Sasaki H., Nishida K., Biol. Pharm. Bull., 28, 1049-1053 (2005).

33) Kawakami S., Hirayama R., Shoji K., Kawanami R., Nishida K., Nakashima M., Sasaki H., Sakaeda T., Nakamura J., Biochem. Biophys. Res. Commun., 294, 46-50 (2002).

34) Hirayama R., Kawakami S., Nishida K., Nakashima M., Sasaki H., Sakaeda T., Nakamura J., Pharm. Res., 20, 328-332 (2003).

35) Hirayama R., Nishida K., Fumoto S., Nakashima M., Sasaki H., Nakamura J., Biol. Pharm. Bull., 27, 1697-1699 (2004).

36) Hirayama R., Fumoto S., Nishida K., Nakashima M., Sasaki H., Nakamura J., Biol. Pharm. Bull., 28, 2166-2169 (2005).

37) Hirayama R., Nishida K., Fumoto S., Nakashima M., Sasaki H., Nakamura J., Biol. Pharm. Bull., 28, 181—184 (2005). 
38) Kawakami S., Fumoto S., Nishikawa M., Yamashita F., Hashida M., Pharm. Res., 17, 306-313 (2000).

39) Matsukura N., Onda M., Hasegawa H., Tokunaga A., Hoshino A., Igarashi T., Suzuki S., Shimada T., Jpn. J. Cancer Chemother, 24 1778-1780 (1997).

40) Tanaka T., Kanai F., Lan K. H., Ohashi M., Shiratori Y., Yoshida Y., Hamada H., Omata M., Biochem. Biophys. Res. Commun., 231, 775779 (1997).

41) Heideman D. A. M., van Beusechem V. W., Offerhaus G. J. A., Wick- ham T. J., Roelvink P. W., Craanen M. E., Pinedo H. M., Meijer C. J. L. M., Gerritsen W. R., Hum. Gene Ther, 13, 1677-1685 (2002).

42) Janunger K. G., Hafström L., Nygren P., Glimelius B., Acta Oncol., 40, 309-326 (2001).

43) Kim R., Minami K., Nishimoto N., Toge T., Int. J. Oncol., 18, 363 367 (2001)

44) Fillat C., Carrio M., Cascante A., Sangro B., Curr. Gene Ther, 3, 1326 (2003). 